\title{
Microstructural Evolution of Mo-Si-B Ternary Alloys Through Heat Treatment at $1800^{\circ} \mathrm{C}$
}

\author{
Kyosuke Yoshimi ${ }^{1,}$ a , Seong-Ho Ha ${ }^{2, b}$, Kouichi Maruyama ${ }^{1, \mathrm{c}}$, Rong $\mathrm{Tu}^{3, \mathrm{~d}}$ \\ and Takashi Goto ${ }^{3, e}$ \\ ${ }^{1}$ Graduate School of Environmental Studies, Tohoku University, Sendai 980-8579, Japan \\ ${ }^{2}$ Graduate Student, Graduate School of Environmental Studies, Tohoku University, Sendai \\ 980-8579, Japan \\ ${ }^{3}$ Institute for Materials Research, Tohoku University, Sendai 980-8577, Japan \\ ayoshimi@material.tohoku.ac.jp, bhsh1999@m.tains.tohoku.ac.jp, \\ cmaruyama@material.tohoku.ac.jp, ${ }^{d}$ turong@imr.tohoku.ac.jp, ${ }^{\mathrm{e}}$ goto@imr.tohoku.ac.jp
}

Key words: intermetallic compound, molybdenum, silicon, boron, phase diagram, heat treatment, microstructure.

\begin{abstract}
First of all, the as-cast microstructures of Mo-rich Mo-Si-B ternary alloys were investigated around the triple junction point of the primary Mo solid solution, $\mathrm{Mo}_{5} \mathrm{SiB}_{2}$ and $\mathrm{Mo}_{2} \mathrm{~B}$ in this work, based on the liquidus projections of the Mo-Si-B system which have been reported in earlier studies. Subsequently, their microstructural evolution through heat treatment was investigated. Since $\mathrm{Mo}_{2} \mathrm{~B}$ crystallizes out during solidification into a primary or secondary phase even though the alloy composition lies in the triangle of $\mathrm{Mo}-\mathrm{Mo}_{5} \mathrm{SiB}_{2}-\mathrm{Mo}_{3} \mathrm{Si}$ in the Mo-Si-B equilibrium phase diagram, the as-cast microstructures include the non-equilibrated $\mathrm{Mo}_{2} \mathrm{~B}$ in wide compositional ranges. However, $\mathrm{Mo}_{2} \mathrm{~B}$ was completely decomposed during heat treatment at $1800{ }^{\circ} \mathrm{C}$ for $24 \mathrm{~h}$ and this contributed to the development of homogeneous, fine microstructures. On the other hand, since $\mathrm{Mo}_{2} \mathrm{~B}$ was not decomposed perfectly during $24 \mathrm{~h}$ of $1600{ }^{\circ} \mathrm{C}$ heat treatment, as-cast microstructures largely remained. Therefore, it is realized that the heat treatment at $1800{ }^{\circ} \mathrm{C}$ is necessary to obtain well-developed microstructures of Mo-Si-B alloys.
\end{abstract}

\section{Introduction}

Mo-Si-B ternary alloys containing Mo solid solution $\left(\mathrm{Mo}_{\mathrm{ss}}\right), \mathrm{Mo}_{3} \mathrm{Si}$ and $\mathrm{Mo}_{5} \mathrm{SiB}_{2}\left(\mathrm{~T}_{2}\right)$ are one of greatly promising candidates as ultra-high temperature structural materials beyond Ni-base superalloys. Several efforts have been dedicated to understand the phase formation and stability and the solidification pathways of Mo-Si-B ternary alloys [1-6]. Liquidus projection charts play an important role in understanding the sequences of phase formation from liquid to a final microstructure of an alloy. A number of the liquidus projections obtained either experimentally or thermodynamically calculated have been reported for the Mo-Si-B system. Nunes et al. [2,3] were the first to publish their projection in 1997, showing the solidification pathways for each primary phase region with their corresponding microstructures. Katrych et al. also published their melting diagram of the Mo-Si-B system [4]. After those, Yang and Chang reconsidered the system using a thermodynamic modeling approach [5]. Despite the attention this system has been getting, some minor discrepancies remain between the studies, particularly with regard to as-cast microstructures and their phase developments during heat treatment.

Some equilibrium ternary phase diagrams have been also proposed for the Mo-Si-B system. Nowotny et al. presented a Mo-Si-B phase diagram at $1600{ }^{\circ} \mathrm{C}$ in 1957 [1]. Nunes et al. redrew it 40 years later (1997) [2], and Kim and Perepezko modified it recently (2006) [6]. Microstructural studies have been extensively conducted for the Mo-Si-B system based on the equilibrium ternary phase diagram at $1600{ }^{\circ} \mathrm{C}$ [e.g. 7-12]. However, studies concerning the microstructural evolution by heat treatment correlated with as-cast microstructure are few and far between. 
Table 1 Weighed and chemically analyzed compositions of Alloys $1-4$ [at.\%].

\begin{tabular}{c|cc|cc}
\hline \multirow{2}{*}{ Alloy No. } & \multicolumn{2}{|c|}{ Weighed composition } & \multicolumn{2}{c}{ Chemically analyzed composition } \\
\cline { 2 - 5 } & $\mathrm{Si}$ & $\mathrm{B}$ & $\mathrm{Si}$ & $\mathrm{B}$ \\
\hline \hline 1 & 9.5 & 14.2 & 9.28 & 14.05 \\
2 & 6.6 & 13.2 & 6.52 & 13.03 \\
3 & 10.5 & 14.2 & 10.76 & 14.46 \\
4 & 8.7 & 17.4 & 8.47 & 17.21 \\
\hline
\end{tabular}

In this study, the as-cast microstructures were investigated around the triple junction point of primary Mo solid solution $\left(\mathrm{Mo}_{\mathrm{ss}}\right), \mathrm{Mo}_{5} \mathrm{SiB}_{2}\left(\mathrm{~T}_{2}\right)$ and $\mathrm{Mo}_{2} \mathrm{~B}$, based on the liquidus projections of the Mo-Si-B system reported reported by Yang and Chang [5]. This was followed by an investigation into their microstructural change due to heat treatment at $1600{ }^{\circ} \mathrm{C}$ or $1800^{\circ} \mathrm{C}$. The microstructure evolution will be discussed by comparing the microstructures before and after heat treatment.

\section{Experimental Procedures}

Four kinds of alloys were prepared by an arc-melting technique from pure Mo (99.9 wt.\%), Si (99.9999 wt.\%) and B (99.95 wt.\%) in an Ar atmosphere. The weighed and chemically analyzed compositions of the four alloys are given in Table 1. Details with regard to sample preparation and chemical analyses are described in our previous paper [13]. Half of one ingot for each alloy was annealed at 1600 or $1800{ }^{\circ} \mathrm{C}$ for $24 \mathrm{~h}$ in Ar at atmospheric pressure. Their microstructures before and after the heat treatment were observed by scanning electron microscopy (SEM) with back scattered electron images (BSE). Their constituent phases were identified by X-ray diffractometry (XRD). A Quantitative composition analysis was performed using an electron probe micro-analyzer (EPMA). The details of how the quantitative composition analysis data were calibrated are also given in our previous paper [13]. Microstructure observation and qualitative composition analysis

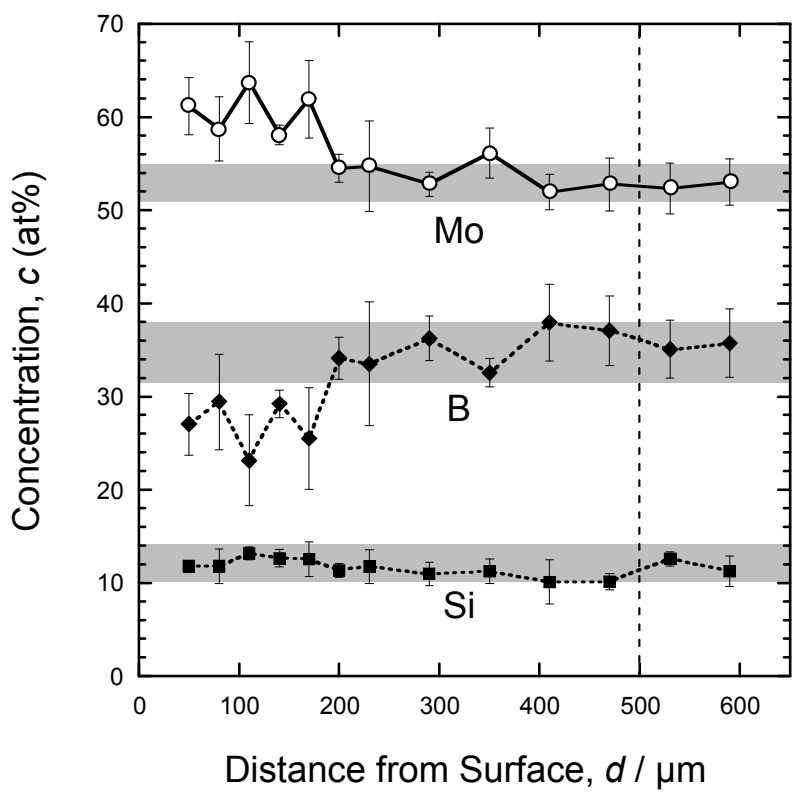

Fig. 1 Change in concentration of Mo, Si and B by EPMA after the heat treatment at $1800{ }^{\circ} \mathrm{C}$ for $24 \mathrm{~h}$ in an Ar atmosphere. 


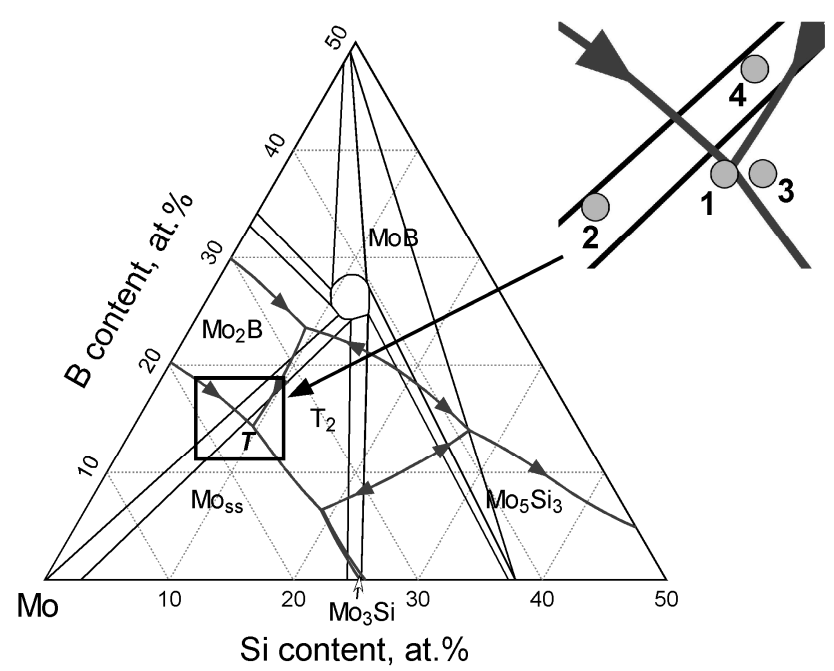

Fig. 2 Chemical compositions of the four different alloys examined in this study. Red (thick) lines correspond to the liquidus projection reported by Yang and Chang [5] and black (thin) lines correspond to the ternary phase diagram at $1600{ }^{\circ} \mathrm{C}$ reported by Kim et al. [6].

were also conducted using a transmission electron microscope (TEM) operated at $300 \mathrm{kV}$ equipped with an energy dispersive X-ray spectroscope (EDX).

An additional sample was produced by powder-processing in order to check compositional degradation during heat treatment. Mo-Si-B powder with an average composition determined by EPMA as Mo-(12.0 \pm 2.0$)$ at.\%. Si- $(34.7 \pm 3.1)$ at.\% B was consolidated using a spark-plasma sintering machine operated at $1600{ }^{\circ} \mathrm{C}$ and $65 \mathrm{MPa}$ for $10 \mathrm{~min}$. The compositional degradation from the surface after the heat treatment at $1800{ }^{\circ} \mathrm{C}$ for $24 \mathrm{~h}$ was quantitatively measured by EPMA.

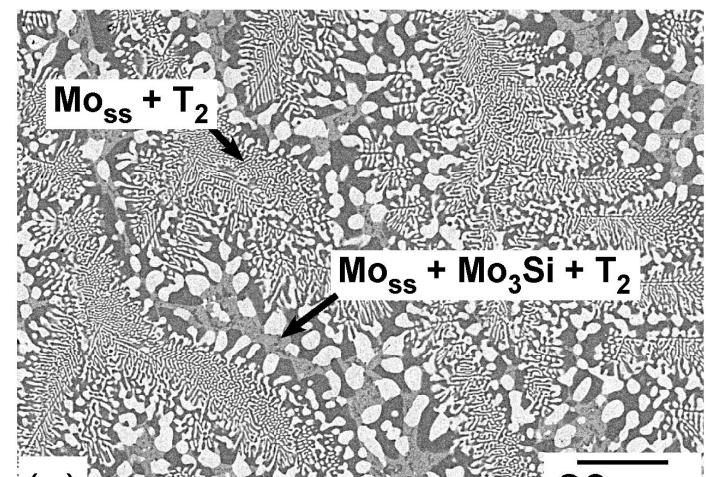

(a)

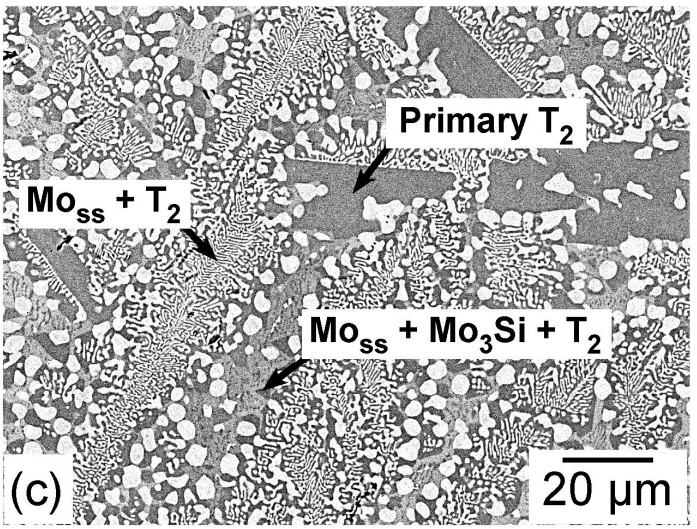



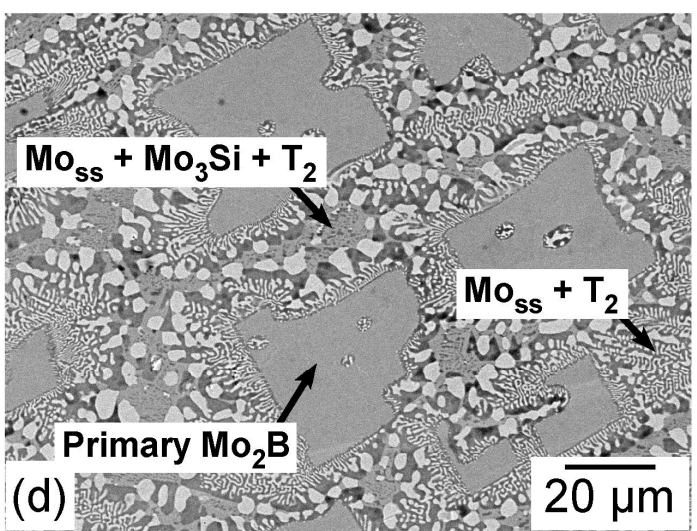

Fig. 3 BSE images of as-cast microstructures of Alloys 1 - 4. (a) Alloy 1, (b) Alloy 2, (c) Alloy 3 and (d) Alloy 4. 


\section{Results and Discussion}

During the heat treatment at $1800{ }^{\circ} \mathrm{C}$ for $24 \mathrm{~h}$, compositional degradation occurred near the surface. Fig. 1 shows the change in concentration of Mo, $\mathrm{Si}$ and $\mathrm{B}$ from the surface according to EPMA measurements. The gray zones indicate the standard deviations against the average concentrations of the elements in a non-heat-treated specimen. Si concentration was almost constant from the surface to inside. However, Mo concentration was more than 5 at.\% higher and B concentration more than 5 at.\% lower near surface than inside and in the non-heat-treated specimen. The enrichment of Mo and the depletion of B resulted mainly from the evaporation of B from the surface during heat treatment even when in an Ar atmospheric pressure. No compositional degradation appears under a depth deeper than $500 \mu \mathrm{m}$, as shown in Fig. 1. Considering these results, all of the previously mentioned microstructural observation and phase identification techniques were conducted on the inner parts of the ingot, in regions significantly deeper than $500 \mu \mathrm{m}$ from the surface.

The chemical compositions of the four different alloys produced by Ar arc-melting are plotted in Fig. 2, which includes the projection of the liquidus surface of the Mo-Si-B system as calculated by Yang and Chang [5] overlapped with the ternary phase diagram at $1600{ }^{\circ} \mathrm{C}$ produced by Kim et al. [6]. The composition of Alloy 1 was almost at the triple junction point of the $\mathrm{Mo}_{\mathrm{ss}}, \mathrm{T}_{2}$ and $\mathrm{Mo}_{2} \mathrm{~B}$ primary phases (the so-called " $T$ " point) in the liquidus projection and inside the $\mathrm{Mo}_{\mathrm{ss}}-\mathrm{T}_{2}-\mathrm{Mo}_{3} \mathrm{Si}$ three-phase region of the ternary phase diagram. The composition of Alloy 2 lay completely in the primary $\mathrm{Mo}_{\mathrm{ss}}$ region of the liquidus projection and in the $\mathrm{Moss}_{\mathrm{ss}}-\mathrm{T}_{2}$ two-phase region of the ternary phase diagram. In the case of Alloy 3, its composition lay in the primary $\mathrm{T}_{2}$ region of the liquidus projection and inside the $\mathrm{Mo}_{\mathrm{ss}}-\mathrm{T}_{2}-\mathrm{Mo}_{3} \mathrm{Si}$ three-phase region of the ternary phase diagram. The composition of Alloy 4 lies in the primary $\mathrm{Mo}_{2} \mathrm{~B}$ region in the liquidus projection plot and in the $\mathrm{Mo}_{\mathrm{ss}}-\mathrm{T}_{2}$ two-phase region of the ternary phase diagram.

Fig. 3 shows the as-cast microstructures of Alloys $1-4$. As reported in our previous paper [13],

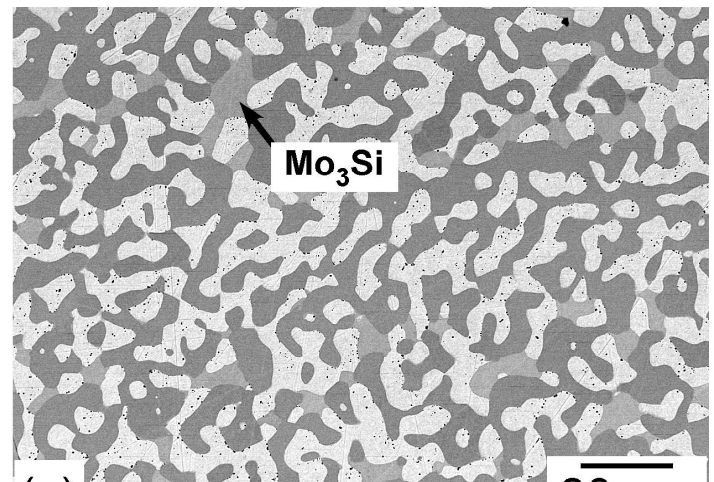

(a)

$2 \overline{20 \mu \mathrm{m}}$
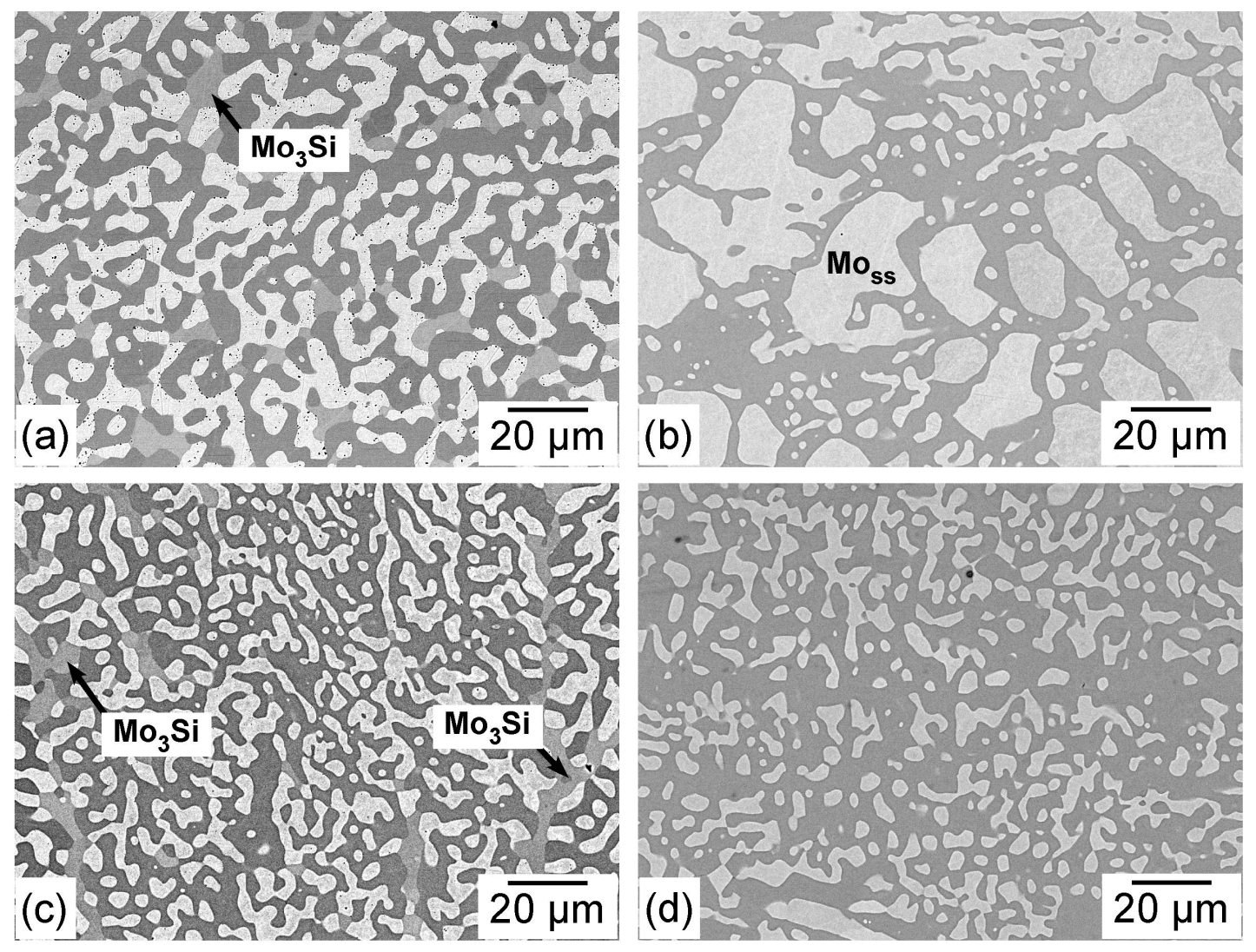

Fig. 4 BSE images of Alloys $1-4$ microstructures after heat treatment at $1800{ }^{\circ} \mathrm{C}$ for $24 \mathrm{~h}$. (a) Alloy 1, (b) Alloy 2, (c) Alloy 3 and (d) Alloy 4. 


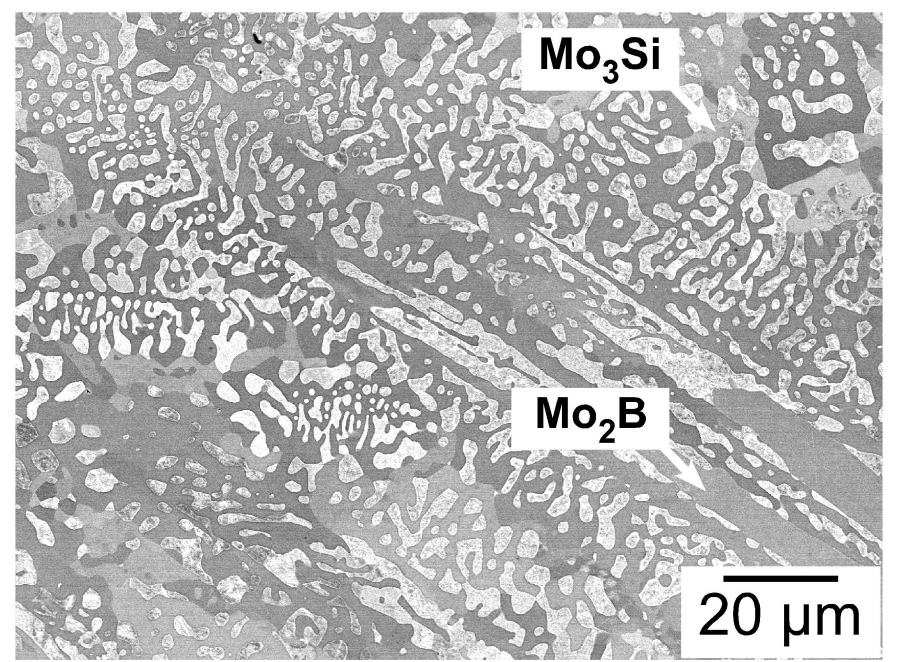

Fig. 5 BSE image of Alloy 4 microstructure after heat treatment at $1600{ }^{\circ} \mathrm{C}$ for 24 hours.

composition dependence on primary phase formation was in excellent agreement with the liquidus projection by Yang and Chang [5]. Alloy 1 had a slight amount of very small primary $\mathrm{Mo}_{\mathrm{ss}}$ areas, superfine $\mathrm{Mo}_{\mathrm{ss}}-\mathrm{T}_{2}$ two-phase eutectic and fine $\mathrm{Mo}_{\mathrm{ss}}-\mathrm{T}_{2}-\mathrm{Mo}_{3} \mathrm{Si}$ three-phase areas. Alloy 2 had large primary $\mathrm{Mo}_{\mathrm{ss}}$ areas, largely-elongated secondary $\mathrm{Mo}_{2} \mathrm{~B}$ areas containing $\mathrm{Mo}_{\mathrm{ss}}$ grains, superfine $\mathrm{Mo}_{\mathrm{ss}}-\mathrm{T}_{2}$ two-phase eutectic and fine $\mathrm{Mo}_{\mathrm{ss}}-\mathrm{T}_{2}-\mathrm{Mo}_{3} \mathrm{Si}$ three-phase areas. As described above, the composition of Alloy 2 was in the $\mathrm{Mo}_{\mathrm{ss}}-\mathrm{T}_{2}$ two-phase region of the ternary phase diagram. Thus, the $\mathrm{Mo}_{2} \mathrm{~B}$ contained in Alloy 2 was not equilibrated at $1600{ }^{\circ} \mathrm{C}$. Alloy 3 had large angular shapes of primary $\mathrm{T}_{2}$, superfine $\mathrm{Mo}_{\mathrm{ss}}-\mathrm{T}_{2}$ two-phase eutectic and fine $\mathrm{Mo}_{\mathrm{ss}}-\mathrm{T}_{2}-\mathrm{Mo}_{3} \mathrm{Si}$ three-phase areas. Alloy 4 had elongated primary $\mathrm{Mo}_{2} \mathrm{~B}$ areas, superfine $\mathrm{Mo}_{\mathrm{ss}}-\mathrm{T}_{2}$ two-phase eutectic and fine $\mathrm{Mo}_{\mathrm{ss}}-\mathrm{T}_{2}-\mathrm{Mo}_{3} \mathrm{Si}$ three-phase areas. The composition of Alloy 4 was also in the $\mathrm{Mo}_{\mathrm{ss}}-\mathrm{T}_{2}$ two-phase region of the ternary phase diagram, and thus Alloy 4 also contained $\mathrm{Mo}_{2} \mathrm{~B}$ non-equilibrated at $1600{ }^{\circ} \mathrm{C}$.

Fig. 4 shows the microstructures of Alloys $1-4$ after heat treatment at $1800{ }^{\circ} \mathrm{C}$ for $24 \mathrm{~h}$. The microstructures of all of the alloys drastically changed during heat treatment. Alloy 1 had a homogeneous microstructure consisting of $\mathrm{Mo}_{\mathrm{ss}}, \mathrm{T}_{2}$ networks and a small amount of $\mathrm{Mo}_{3} \mathrm{Si}$ grains, which corresponds well to the ternary phase diagram. From the microstructure observation of Alloy 1 , it is clear that heat treatment at a temperature of $1800{ }^{\circ} \mathrm{C}$ is sufficient to enhance the microstructural evolution of the Mo-Si-B alloys. Alloys 2 and 4 had non-equilibrated $\mathrm{Mo}_{2} \mathrm{~B}$ in their as-cast microstructures, but it disappeared completely during heat treatment. In Alloy 2, the matrix was $\mathrm{T}_{2}$. Some primary $\mathrm{Mo}_{\mathrm{ss}}$ areas are assumed to have merged together and small $\mathrm{Mo}_{\mathrm{ss}}$ grains distributed homogeneously between primary $\mathrm{Mo}_{\mathrm{ss}}$ areas. Alloy 4 had a simple microstructure, that is, small $\mathrm{Mo}_{\mathrm{ss}}$ grains were distributed homogeneously in the matrix of $\mathrm{T}_{2}$. The $\mathrm{Mo}_{\mathrm{ss}}$ and $\mathrm{T}_{2}$ two-phase microstructures in Alloys 2 and 4 also correspond to the ternary phase diagram. $\mathrm{Mo}_{3} \mathrm{Si}$ was occasionally observed in Alloys 2 and 4, suggesting that the compositions of Alloys 2 and 4 stand on the phase boundary between $\mathrm{Mo}_{\mathrm{ss}}-\mathrm{T}_{2}$ and $\mathrm{Mo}_{\mathrm{ss}}-\mathrm{T}_{2}-\mathrm{Mo}_{3} \mathrm{Si}$ regions in the ternary phase diagram at 1800 ${ }^{\circ} \mathrm{C}$. In Alloy 3, primary angular $\mathrm{T}_{2}$ areas remained after heat treatment, with a homogeneous microstructure consisting of $\mathrm{Mo}_{\mathrm{ss}}, \mathrm{T}_{2}$ and $\mathrm{Mo}_{3} \mathrm{Si}$ grains developed between the $\mathrm{T}_{2}$ areas.

On the other hand, microstructural evolution was not sufficiently achieved during heat treatment at $1600{ }^{\circ} \mathrm{C}$ for $24 \mathrm{~h}$ for the Mo-Si-B alloys. Fig. 5 shows an example of the microstructure observed of Alloy 4 heat-treated at $1600{ }^{\circ} \mathrm{C}$ for $24 \mathrm{~h}$. Not only did a significant amount of primary $\mathrm{Mo}_{2} \mathrm{~B}$ areas remained, but the microstructure development between the primary areas was insufficient in the entire specimen. Consequently, it is clear that the heat treatment at $1600^{\circ} \mathrm{C}$ for $24 \mathrm{~h}$ is inadequate and that a temperature of $1800^{\circ} \mathrm{C}$ is necessary to obtain a well-developed microstructure from as-cast Mo-Si-B alloys, which should be stable at ultra-high temperatures. 


\section{Conclusions}

In this work, the microstructural evolution from as-cast states was investigated for the Mo-Si-B alloys after heat treatment at 1600 or $1800^{\circ} \mathrm{C}$ for $24 \mathrm{~h}$. Microstructures after heat treatment at $1800{ }^{\circ} \mathrm{C}$ for 24 $\mathrm{h}$ were strongly influenced by their as-cast microstructures. Primary phases of $\mathrm{Mo}_{\mathrm{ss}}$ and $\mathrm{T}_{2}$ remained, but primary or secondary $\mathrm{Mo}_{2} \mathrm{~B}$ was completely decomposed, contributing to the development of homogeneous, fine $\mathrm{Mo}_{\mathrm{ss}}-\mathrm{T}_{2}$ or $\mathrm{Mo}_{\mathrm{ss}}-\mathrm{T}_{2}-\mathrm{Mo}_{3} \mathrm{Si}$ microstructures since the compositions of the alloys lie in the two or three phase region and $\mathrm{Mo}_{2} \mathrm{~B}$ is not in equilibrium at that temperature. On the other hand, $\mathrm{Mo}_{2} \mathrm{~B}$ was not decomposed perfectly during heat treatment at $1600{ }^{\circ} \mathrm{C}$ for $24 \mathrm{~h}$, and thus microstructure development was not sufficient after the treatment. Therefore, it is realized that heat treatment needs to be carried out at $1800{ }^{\circ} \mathrm{C}$ in order to obtain well-developed microstructures of the Mo-Si-B alloys.

\section{Acknowledgment}

Mr. Y. Murakami of Institute for Materials Research, Tohoku University for his assistance to operate EPMA. This work was supported by Global COE Program "Materials Integration (International Center of Education and Research), Tohoku University", MEXT, Japan and the Grant-in-Aid for Science Research from the Ministry of Education, Culture, Sports, Science and Technology of Japan, Under Contract No. 21360334.

\section{References}

[1] H. Nowotny, R. Kieffer and F. Benesovsky: Planseeberichte Fuer Pulvermetallurgie 5 (1957), p. 86.

[2] C.A. Nunes, R. Sakidja and J.H. Perepezko, in: Structural Intermetallics 1997, edited by M.V. Nathal, R. Darolia, C.T. Liu, P.L. Martin, D.B. Miracle, R. Wagner and M. Yamaguchi, TMS, Warrendale, PA (1997), pp. $831-839$.

[3] C.A. Nunes, R. Sakidja, Z. Dong and J.H. Perepezko: Intermetallics 8 (2000), p. 327.

[4] S. Katrych, A. Grytsiv, A. Bondar, P. Rogl, T. Velikanova and M. Bohn: J. Alloy. Comp. 347 (2002), p. 94.

[5] Y. Yang and Y.A. Chang: Intermetallics 13 (2005), p. 121.

[6] S.T. Kim and J.H. Perepezko: J. Phase Equilib. Diffus. 27 (2006), p. 605.

[7] J.H. Schneibel, C.T. Liu, D.S. Easton and C.A. Carmichael: Mater. Sci. Eng. A261 (1999), p. 78.

[8] R. Sakidja, J. Myers, S. Kim and J.H. Perepezko: Int. J. Refrac. Met. Hard Mater. 18 (2000), p. 193.

[9] J.H. Schneibel, R.O. Ritchie, J.J. Kruzic and P.F. Tortorelli: Metall. Mater. Trans. A 36A (2005), p. 525.

[10] J.J. Kruzic, J.H. Schneibel and R.O. Ritchie: Metall. Mater. Trans. A 36A (2005), p. 2393.

[11] F. Wang, A. Shan, X. Dong and J. Wu: J. Alloy. Comp. 462 (2008), p. 436.

[12] M. Heilmaier, M. Krüger, H. Saage, J. Rösler, D. Mukherji, U. Glatzel, R. Völkl, R. Hüttner, G. Eggeler, Ch. Somsen, T. Depka, H.-J. Christ, B. Gorr and S. Burk: JOM 61 (July 2009), p. 61.

[13] S.-H. Ha, K. Yoshimi, K. Maruyama, R. Tu and T. Goto: Mater. Trans., submitted. 